\title{
Business Strategy Formulation for Art Merchandise Brand (Case Study: Gutsy Prune)
}

\author{
Natalie Amadea*, Mustika Sufiati Purwanegara
}

School of Business and Management ITB, Indonesia

\begin{abstract}
A part of Indonesia's creative industries is the art merchandise industry which is dominated by independent visual artists who establish their art merchandise brands to market original art merchandise. Visual artists try to apply the principles of entrepreneurship in their practice since entrepreneurship has a fundamental role in their artistic careers. A business strategy is needed for any art merchandise brand. To develop a business strategy that is based on the empirical case, an Indonesian art merchandise brand called Gutsy Prune is analyzed as a case study. Gutsy Prune needs to develop a business strategy to boost the sales stagnation and to ensure the business continuity within the art merchandise market. The methodology for the research is a qualitative method and it is executed by conducting in-depth interviews with Gutsy Prune's potential and current customers. The results from the interview will be treated as the primary data along with observation and competitor analysis, while information from literature research will be used as secondary data to support the primary data. The focus of the research is the formulation of a business strategy for the art merchandise brand and the data collection was conducted by using interviews, observation, competitor analysis, and literature research. Gutsy prune needs to have a business strategy to tackle the sales stagnation that is caused by the low rate of inventory turnover. Before formulating a business strategy to boost sales stagnation, a series of analysis that includes environmental scanning and customer analysis is performed. The result from the aforementioned analysis is further examined by using SWOT Analysis to discover the root causes of the sales stagnation. It has been concluded that Gutsy Prune possesses some weaknesses in its segmentation, targeting, positioning, value proposition, marketing mix, and organizational structure. To resolve the root causes, Gutsy Prune develops a business strategy that contains STP Strategy, Value Proposition Canvas, Marketing Mix Strategy, organizational structure design, and a generic competitive strategy to sums up the business strategy's direction. From the research, Gutsy Prune can establish a one-year implementation plan to execute the business strategy.
\end{abstract}

Keywords: creative industries, art merchandise, visual artists, business strategy, value proposition

\section{INTRODUCTION}

The main scope of this research is the creative industries in Indonesia, especially the art merchandise industry. Nowadays the art merchandise industry is dominated by independent visual artists who establish their art merchandise brands. New entrants are also starting to penetrate the market over the past few years and it leads to increased competition in Indonesia's art merchandise industry. Within the art merchandise industry, numerous visual artists try to apply the principles of entrepreneurship in their careers since entrepreneurship has a fundamental role in the survival of their professional artistic careers. They apply the entrepreneurship method by actively creating art merchandise from their original artwork and turning it into artisan-made products that are unique and also marketable. Recently, many creative bazaars and art markets have sprung up in Indonesia. Some of the most well-known local creative markets are Semasa Creative Market, PoP Market, and The Local 
Market. With the emergence of many local creative markets, it can be concluded that the art merchandise industry has its niche market and it attracts customers who are interested in art and craft.

To observe the art merchandise brand empirically to formulate a suitable business strategy, an Indonesian art merchandise brand called Gutsy Prune is taken as a case study for the research. Gutsy Prune is an art merchandise brand that is established in 2018 by an illustrator. Gutsy Prune focuses on creating art merchandise such as illustrated apparel, accessories, and paper goods. Gutsy Prune is currently run by one person which has a position as an owner who makes all the decisions in the Gutsy Prune business process and also as an illustrator who creates all artwork that is used for Gutsy Prune products. The owner does all activities in Gutsy Prune's business process including product designing process, order management, inventory management, and customer service. In the production process, the owner is responsible for the quality control process, while Gutsy Prune's production partners handle the product manufacturing. Gutsy Prune's current sales channels are Etsy.com and Instagram. In the last six months, from June until November 2019, Gutsy Prune has not managed to sell all of its stock because the company currently has limited customers and it affects the company's revenue stream where Gutsy Prune is not able to generate a stable revenue from product sales.

A business strategy is needed not only to resolve Gutsy Prune's sales stagnation but also to ensure the business continuity within the competitive art merchandise market in the long run. With analyzing the current business issue of Gutsy Prune, the research aims to make an original contribution by formulating a business strategy that helps art merchandise brands to boost sales stagnation and to find the product-market fit. The business strategy formulation mainly focuses on the marketing strategy and the operations strategy to boost sales stagnation.

\section{LITERATURE REVIEW}

To be able to formulate a business strategy for Gutsy Prune as an art merchandise brand, research will be executed and it involves analysis from the data resources, art merchandise business trend, and Gutsy Prune owner's hands-on experience in the art merchandise business. The daily business process of Gutsy Prune will be carefully evaluated to be able to spot the root causes of sales stagnation that occurs in the business. The observation process will be supported by the usage of social media as the primary tool to extract data and insights from the art merchandise market. The data will be analyzed to form a hypothesis that supports the formulation process of a business strategy for Gutsy Prune. The analysis for the research will be firstly performed by using environmental scanning. According to Wheelen \& Hunger (2012), in their book titled Strategic Management and Business Policy Toward Global Sustainability, environmental scanning is a type of analysis tool that requires information observation, evaluation, and dispersion from both external and internal environments. The purpose of environmental scanning is to identify strategic factors and all data gathered from the external and internal environments could be used as foundations to plan a company's business strategy (p.16).

The first step of environmental scanning is to conduct an internal analysis. According to David \& David (2017) in Strategic Management: A Competitive Advantage Approach, internal analysis is used to identify internal strengths and weaknesses that are complementary to the external environment analysis which is used to discover opportunities and threats. The combination of external and internal environment analysis can form the basis needed to formulate a business strategy. A company established a business strategy to capitalize on the company's internal strengths and overcoming the company's weaknesses (p.178). The internal environment of Gutsy Prune will be analyzed by using STP Analysis, 4Ps Marketing Mix Analysis, and Value Chain Analysis. The external analysis is the last step of 
environmental scanning. David \& David (2017) stated that external analysis focuses on identifying and evaluating trends and events such as increased competition or population shifts. External analysis is conducted to reveal some primary opportunities and threats that are currently faced by a company. By knowing the existing opportunities and threats, a company can formulate a business strategy that takes advantage of the existing opportunities and also reduce the impact of threats (p.218). The external environment of Gutsy Prune will be analyzed by using PESTEL Analysis, Porter's Five Forces Analysis, Competitor Analysis, and Strategic Group Mapping.

The analysis from environmental scanning will be validated by conducting a customer analysis. According to David \& David (2017), customer analysis is the examination and discovery of customers' needs and wants which could involve conducting a customer survey to develop customer profiles. Customer profiles can reveal the demographic characteristics of a company's customers. The successful company continuously monitors its current and potential customers' buying behavior. Customer analysis is an integral part of business strategy planning (p.188). Gutsy Prune conducts in-depth phone interviews with its current customers and potential customers to extract the customers' honest insights regarding their perspective on art merchandise brands, their satisfaction towards Gutsy Prune's products, the attractiveness of the art merchandise products, their experiences, and also their expectations of Indonesia's art merchandise industry. The in-depth phone interview method is chosen because according to Hague (2006), in the book titled A Practical Guide To Market Research, in-depth interviews are best used as a market research method when the objective of the research is to obtain several deep insights and understandings of customer behavior. This method is qualitative and it implies that the objective is to discover data that emphasizes its quality over its quantity. An in-depth interview is used in this research because it is exploratory and it also involves unstructured techniques based on small samples. The data arising from the in-depth interviews are largely feedbacks and responses in the form of words from the respondents (p.42).

\section{METHODOLOGY}

The research will be conducted by referring to some published academic resources such as books, journals, and online sources to be able to formulate an effective business strategy for art merchandise brands that are facing sales stagnation. According to Henry (2008) in Understanding Strategic Management, a business strategy describes how a company is going to compete in a specific target market. A business strategy is formulated so that a company could achieve a distinctive competitive advantage compared to its competitors (p.18). The first step of the research is to perform environmental scanning from both external and internal environments. The research continues to customer analysis by conducting in-depth phone interviews with seven of Gutsy Prune's current customers and seven of Gutsy Prune's potentials customers. The objectives of this qualitative research by using a depth interview are:

- Exploring and understanding customers' needs,

- Testing reactions to concepts such as art merchandise products, customer services, and approaches to buying,

- Finding out what the real issues or problems are in the art merchandise market,

- Customers' interest, perception, intention to buy, expectation, and experience toward art merchandise products.

The interviews for both potential and current customers of Gutsy Prune were conducted in a period between 2nd December 2019 until 5th December 2019. Each interviewee was interviewed by 
telephone. The individuals that are involved in the interviews are those who meet the predetermined criteria.

Tabel 1. In-depth Interview Participant Profile

\begin{tabular}{ll}
\hline Number of Participants & 14 \\
\hline Gender & Females \\
\hline Location & Jakarta, Bandung \\
\hline Age & 18 -34 years old \\
\hline Occupation & Private employees, Students, Entrepreneurs, Visual artists \\
\hline Interests & Art, Craft, Fashion, Music, Literature \\
\hline
\end{tabular}

According to Maxwell (1996), the process of choosing what time, interview method, and individuals to observe in the interview is called sampling and it is one of the four main components in the qualitative study (p.65). Maxwell (1996) also stated that it is advised that in a small-scale interview to deliberately set cases, individuals, and situations that are known to be typical. A small sample that has been systematically selected for typicality and relative homogeneity provides far more accurate that the conclusions from a large sample that are taken from a random sampling method or accidental variation (p.71). Creswell (2009) also affirmed that in qualitative interviews, the researcher must conduct face-toface interviews with participants. Interviews also can be done by telephone or involving some focus groups with six to eight interviewees in each group. These interviews involve unstructured and generally open-ended questions that are few and intended to elicit views and opinions from the interviewees (p.168). Based on the aforementioned theory or basis, seven of Gutsy Prune's current customers and seven potential customers were interviewed because those numbers are believed to be suited for a small-scale interview in a qualitative study. Those numbers are also chosen because up until now, Gutsy Prune still has a low number of customers and has not done any recording regarding its past customers' data.

The research will employ the primary data taken from the customer interview, observation, and competitor analysis, while the secondary data is collected from books, articles, journals, and other online sources. The result of environmental scanning and customer analysis will be further mapped by performing a SWOT analysis to discover the root causes of the sales stagnation. The root causes will become the primary reasons why some business elements of Gutsy Prune may require some solutions and improvements. The collection of business solutions will form an overall business strategy for Gutsy Prune to boost its sales stagnation

\section{RESULTS AND DISCUSSION}

After some data has been analyzed through the environmental scanning and validated with customer analysis, the conclusions are being summarized in the SWOT analysis. Kotler (2002) in his book titled Marketing Management Millennium Edition, stated that the overall summary of a company's 
strengths, weaknesses, opportunities, and threats is called SWOT. A SWOT analysis consists of an examination from external and internal environments to spot the company's strengths, weaknesses, opportunities, and threats (p.46). The SWOT analysis of Gutsy Prune shows that the existing weaknesses and threats of Gutsy Prune could lead to the discovery of the root causes that directly trigger the sales stagnation. To uncover the root causes of the problem, the root cause analysis diagram will be used. A root cause analysis diagram is performed to discover some causal factors that are related to Gutsy Prune's sales stagnation issue. The root causes will be the foundation of the business strategy formulation for Gutsy Prune. The fundamental causes of Gutsy Prune sales stagnation are lack of human resources, lack of automation in the outbound logistics process, weak STP strategy; weak Marketing Mix strategy; limited sales channels; competitors' wide product-line breadth; competitors' strong online presence on social media platforms; lack of long- term suppliers; and customers' expectations

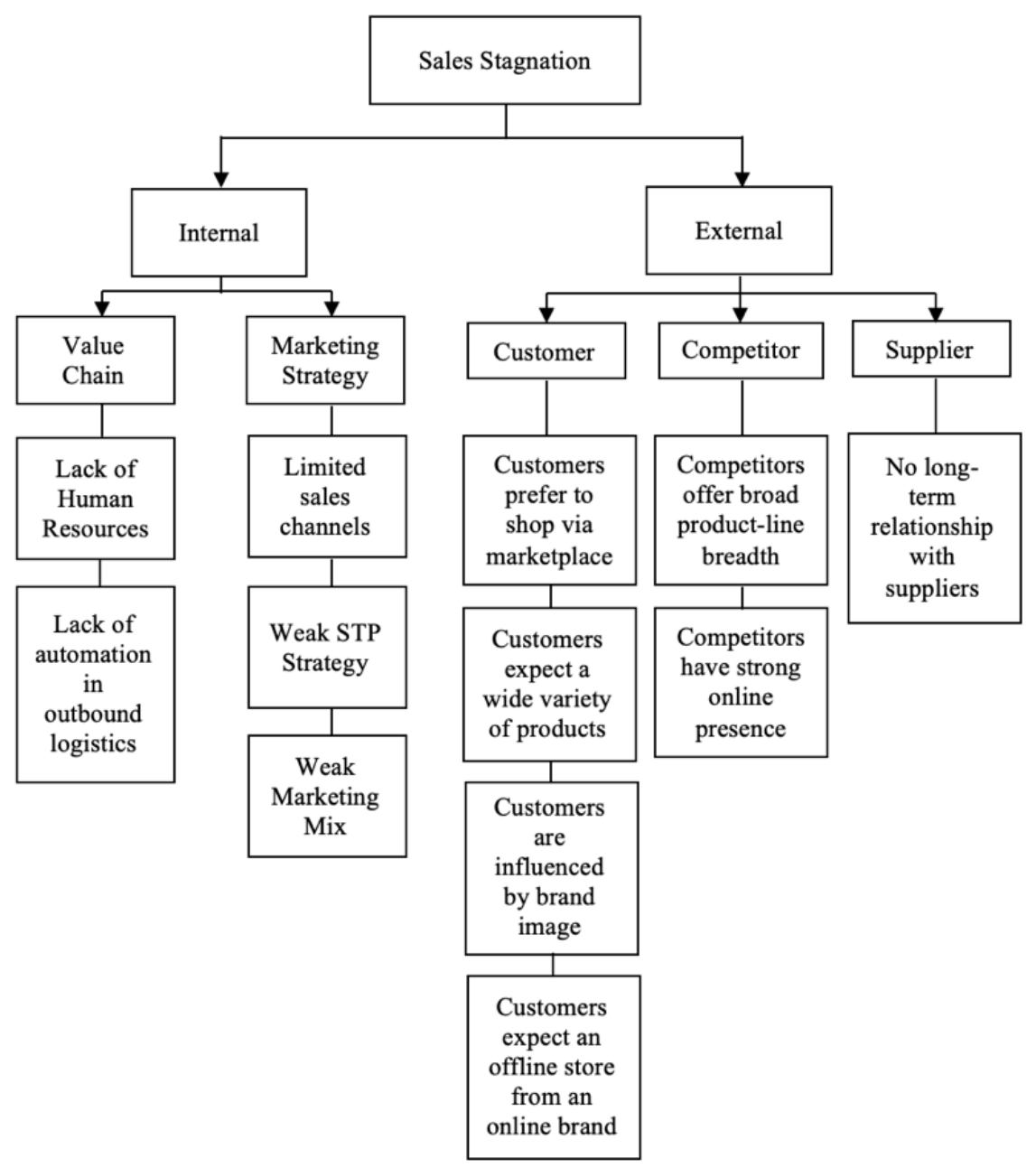

Fig. 1 Root Cause Analysis Diagram 


\section{CONCLUSION}

The research proceeds to the development of business solutions and an implementation plan to achieve the objectives from the business solutions. The proposed business solutions to tackle sales stagnation are: new STP strategy; validated Value Proposition Canvas; new 4Ps Marketing Mix strategy; organizational structure plan; and choosing the most suitable strategy out of Porter's Generic Strategies. The combination of those formulated strategies could form a solid business strategy for Gutsy Prune. In the new STP strategy, Gutsy Prune has targeted its market segment to be Indonesian young adult women, lower-middle to upper-middle class, individuals, whose interests are arts and fashion, individuals who have expressive personality, and individuals who live with a modern lifestyle. Gutsy Prune also positions its brand to be "an alternative and wearable art merchandise brand". The word "alternative" refers to the general theme that Gutsy Prune is trying to apply to its product. Gutsy Prune's illustration work is heavily inspired by a lot of alternative music or movies from the 1970s until the 1980s. Gutsy Prune's illustrations also tend to be unconventional and bold, therefore, the word "alternative" is best used to describe the brand positioning. From the customer analysis, Gutsy Prune manages to formulate a validated Value Proposition Canvas as a foundation to discover product-market fit for Gutsy Prune.

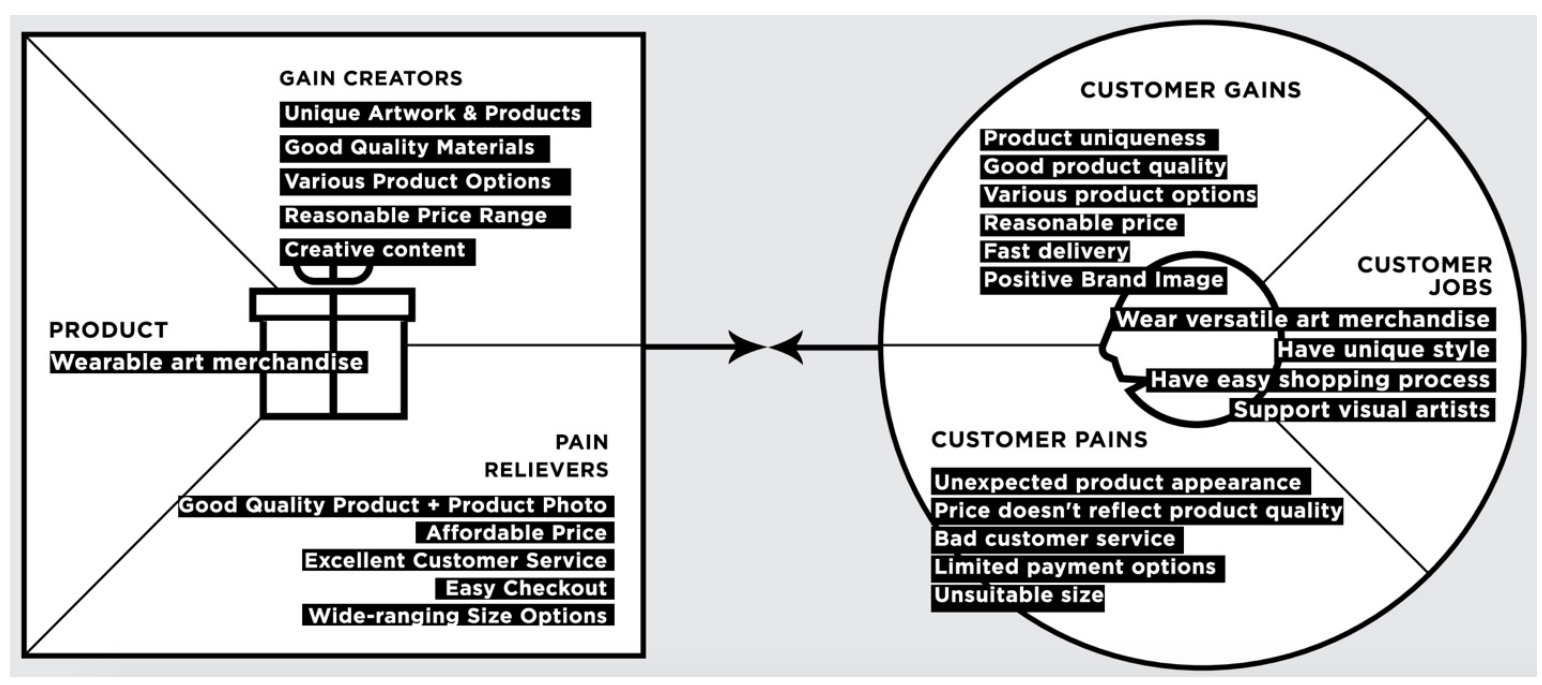

Figure 2. Gutsy Prune's Value Proposition Canvas

From the Value Proposition Canvas, Gutsy Prune offers wearable art merchandise that is assured to have unique artwork, good quality materials, wide product-line breadth, and reasonable price. Gutsy Prune also decided to design its products based on the insights from the customers. Gutsy Prune plans to expand its product-line breadth by creating more accessories and apparel such as shirts, bags, and pins since those categories of products are the most preferred products by the customers. Gutsy Prune also wants to shift to a more eco-friendly method of graphic printing by sourcing production partners that use manual screen printing methods with water-based inks and also apply a waste management system in its production process. The products are set to be in the price range of IDR 50.000 - IDR 250.000 because Gutsy Prune wants to make sure that all products are accessible for lower- 
middle to upper-middle customers. Gutsy Prune also wants to submit a proposal to become a retailer in curated art and gift stores in Jakarta and Bandung because Gutsy Prune needs to reach its customer through offline means. Gutsy Prune also designed an organizational plan design to ensure the continuity of its business process because up until now, Gutsy Prune has been operated by one person who is the owner herself. By hiring a chief of staff, graphic designer, social media manager, inventory officer, and financial officer, the supply chain of Gutsy Prune will run effectively and efficiently. Lastly, From Porter's Generic Competitive Strategies Analysis, Gutsy Prune decides to focus on the differentiation focus strategy as its main business strategy because it suits the value chain of an art merchandise business such as Gutsy Prune. Generally, the differentiation focus strategy of Gutsy Prune is aimed to exploit the special needs of customers from a very specific market segment. Gutsy Prune tends to move toward relatively low-volume and unique art merchandise products. To achieve the objectives of business solutions, Gutsy Prune has set an implementation plan for the next year..

\section{ACKNOWLEDGEMENT}

The author would like to convey her thankfulness to everyone who has either directly or indirectly supported the author to complete this thesis. This gratitude is especially given to Dr. Ir. Mustika Sufiati Purwanegara, M.Sc. as the second author and also the paper counselor, for her continuous guidance, patience, and support during the completion process of this paper. The author would also like to thank all respondents who have participated in the customer interview for this paper.

\section{REFERENCES}

Creswell, John. (2009). Research Design: Qualitative, Quantitative, and Mixed Methods Approaches Third Edition. California, USA: Sage Publications, Inc.

David, Fred. R., \& David, Forest. R. (2017). Strategic Management: A Competitive Advantage Approach. Essex, UK: Pearson Education Limited.

Hague, Paul. (2006). A Practical Guide To Market Research. Surrey, UK: Grosvenor House Publishing Ltd. Henry, Anthony. (2008). Understanding Strategic Management. USA: Oxford University Press.

Kotler, P. (2002). Marketing Management Millennium Edition. Boston, USA: Pearson Custom Publishing Maxwell, Joseph. (1996). Qualitative Research Design: An Interactive Approach. California, USA: Sage Publication, Inc.

Osterwalder et al. (2014). Value Proposition Design. New Jersey, USA: John Wiley \& Sons, Inc.

Wheelen, T.L., \& Hunger, J.D. (2012). Strategic Management and Business Policy Toward Global Sustainability. New Jersey, USA: Pearson Education Inc. 